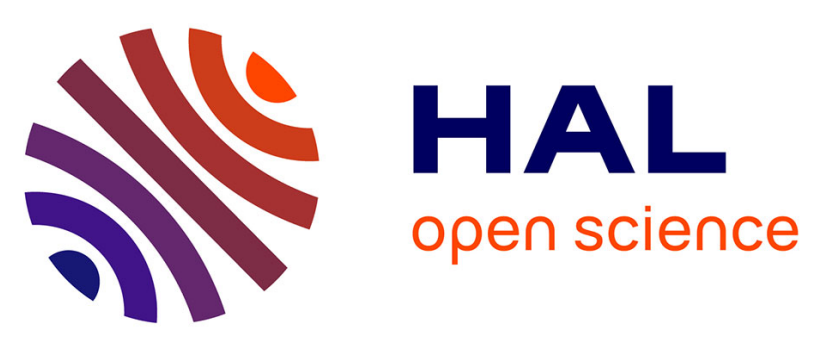

\title{
Microfluidic comparative study of foam flow between a classical and a pH sensitive surfactant
}

\author{
Cyril Micheau, Elisabeth Rosenberg, Loïc Barré, Nicolas Pannacci
}

\section{To cite this version:}

Cyril Micheau, Elisabeth Rosenberg, Loïc Barré, Nicolas Pannacci. Microfluidic comparative study of foam flow between a classical and a pH sensitive surfactant. Colloids and Surfaces A: Physicochemical and Engineering Aspects, 2016, 501, pp.122-131. 10.1016/j.colsurfa.2016.04.061 . hal-01340023

\section{HAL Id: hal-01340023 \\ https://hal.science/hal-01340023}

Submitted on 30 Jun 2016

HAL is a multi-disciplinary open access archive for the deposit and dissemination of scientific research documents, whether they are published or not. The documents may come from teaching and research institutions in France or abroad, or from public or private research centers.
L'archive ouverte pluridisciplinaire HAL, est destinée au dépôt et à la diffusion de documents scientifiques de niveau recherche, publiés ou non, émanant des établissements d'enseignement et de recherche français ou étrangers, des laboratoires publics ou privés. 


\title{
Microfluidic comparative study of foam flow between a classical and a pH sensitive surfactant.
}

Cyril Micheau, Elisabeth Rosenberg, Loïc Barré, and Nicolas Pannacci*

IFP Energies nouvelles, 1-4 avenue de Bois-Préau, 92852 Rueil-Malmaison Cedex - France, telephone :+33147525879; e-mail: nicolas.pannacci@ifpen.fr

\begin{abstract}
Comparative study between foams made of a $\mathrm{pH}$ sensitive surfactant, nonaoxyethylene oleylether carboxylic acid (AKYPO ${ }^{\circledR}$ RO $90 \mathrm{VG}$ ) and a classical foaming surfactant, sodium dodecyl sulphate (SDS) was realised using simple microfluidic devices in the scope of Enhanced Oil Recovery (EOR). The influence of injecting fluid parameters such as gas and foaming liquid pressure was investigated and discussed in terms of foam morphology, and lamellae stability and curvature radii. The increasing stability of AKYPO ${ }^{\circledR}$ foam film lamellae by increasing $\mathrm{pH}$ is classically explained by the electrostatic repulsive interaction of the double layer in foam film. In other hand, the addition of dodecanol (DOH) on SDS solution seems to have no effect on foam regime and lamellae stability except for high $\mathrm{DOH}$ concentration where the foam film shape becomes double bump. The behaviour difference between $A K Y P O \circledR$ and SDS lays on the lamellae shape and stability domain. While SDS lamellae stay unchanged with increasing pressure ratio between the gas and the liquid, AKYPO ${ }^{\circledR}$ lamellae curvature radius increases which could be related to surfactants solubilities and structure. These results pointed out the relevance of solution physicochemical parameters on foam stability and flowing and help the understanding of flowing foam in EOR context.
\end{abstract}

Keywords: foam morphology, lamellae, foam stability, microfluidic, $\mathrm{pH}$ sensitive surfactant, AKYPO.

\section{Introduction}

Liquid foams are non-equilibrium materials[1] composed of a discontinuous gas phase and a liquid phase. Gas is present in the foam in the form of bubbles, spherical in the case of wet foams and polyhedral in the case of dry foams. Liquid foams are used in many process such as ion separation via flotation,[2] nuclear decontamination[3] or explosion confinement.[4] A recent application[5] proposes using foam in Enhanced Oil Recovery (EOR) process in order 
to extract oil in natural reservoirs. This specific application requires the generation of foams in porous media with the aim of reaching and displacing the oil in place. In porous media, foam's definition is more ambiguous because it is presented as a succession of parallel films, called lamellae, joined together by wetting films on the pore walls.[6] Furthermore, when foams are sufficiently confined, 2D-foams are obtained and their bubbles can distort themselves to adopt a spheroid or cylindrical shape.[1,6]

Foam's lamellae are stabilized by surfactant molecules which adsorb at the liquid/gas interface that could change the local surface properties such as surface viscosity, surface tension or elastic moduli.[1,7] These properties directly influence the capacity of the foam to transport gas into porous media which is mainly linked to the foam stability during its generation and flowing.

The higher effective viscosity of foam relatively to gas [8,9] allows to increase the sweep efficiency in porous media and to reduce viscous fingering and gravity segregation due to the low viscosity and the low density of the gas that makes foam a good gas mobility reducing agent.[8,10,11] Moreover, the capacity of foam to accumulate in high-permeability regions reduces gas by-passing by increasing flowing resistance and diverting gas in low permeability pores that improves the EOR process.[12,13] The fundamental understanding of such mechanism is of high importance to better adjust surfactant formulation and extraction process.

Previous works have investigated the physical properties of foam in porous media using lab experiments in sand[14], rocks[10] or micro-device[7,11,15]. Some were interested in the influence of fluid injected parameters on the foam morphology[11] or performance in term of mobility reduction factor[14], and others on the flowing foam behaviour depending on the porous media geometry. $[7,11,15]$. Less study has been focussed on the influence of physicochemicals parameters on foam generation, aging and flowing. It is well known that, surfactant composition and dynamics, salt nature and ionic strength or $\mathrm{pH}[16,17]$ are of crucial importance on the stability of bulk foams (3D-foams) or films. Moreover, for experiments of foam in porous media, chemical composition of the foaming solution is sometimes modified by salt or dye addition, in order to enhance phase contrast[11,18], or by viscosifying or gelling agent to reduce the foam dynamics ( $c f$. aging).

Microfluidic devices are good supports to investigate the influence of physicochemical parameters on foam generation and flowing at the micro-scale. They allowed direct observation of foam with a microscope without using any chemical additive, and a high control level of reproducibility. Coupling with image analysis, and basic image processing, 
thresholding, and skeletisation of the foam image gives qualitative and quantitative informations on foam generation and flowing.

This work proposes a comparative study between a classical surfactant used as a model surfactant in EOR context, sodium dodecyl sulphate (SDS), $[7,8,11,15,18,19]$ and a $\mathrm{pH}$ sensitive surfactant used in metal separation processes, nonaoxyethylene oleylether carboxylic acid (AKYPO® RO 90 VG),[16,20,21] using microfluidics. Foam morphology and stability are analysed in regard to the injected fluid pressures $\left(\mathrm{N}_{2}\right.$ and surfactant solution) and physicochemical parameters such as $\mathrm{pH}$ or dodecanol/SDS concentration ratio. Foam phase diagrams are thus obtained and quantified in terms of bubble size, liquid fraction and topology. Foam flow and stability differences between the two selected surfactants are evidenced regarding lamellae stability domain and curvature radius and discussed putting forward interface properties such as surfactant adsorption and surface viscosity.

\section{Materials and method}

\subsection{Microfluidic device}

Standard soft lithography in PDMS (PolyDiMethylSiloxane) was used for the microfabrication, whose principle was previously described by Duffy et al.[22] Quasi 2D device with a constant depth $(40 \mu \mathrm{m})$ was thereby obtained. Bonding of PDMS on glass with plasma cleaner[23] gives hydrophilic channel surface. Due to the reversibility of this treatment i.e. channel internal surface becomes hydrophobic after few hours, microfluidic device was renewed for each experiment.

Microfluidic devices used for foam flow experiments are composed of two entrances for gas and surfactant aqueous phase, a cross junction for bubble formation, a chamber for the foam observation of $1200 \mu \mathrm{m}$ width $W$ and $3000 \mu \mathrm{m}$ length, and a straight channel (60 $\mu \mathrm{m}$ width) connected to the outside (atmospheric pressure) (see Fig 1). The depth $H$ of the microchannel is constant and equal to $40 \mu \mathrm{m}$.

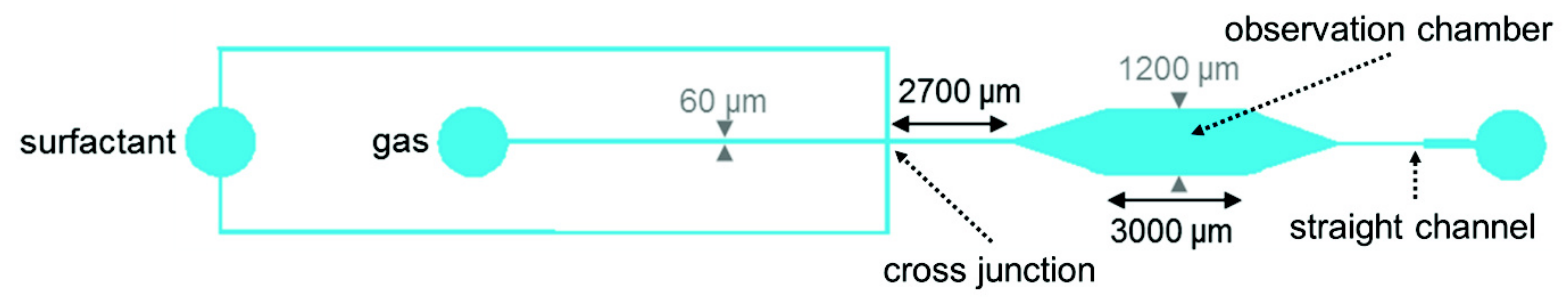

Fig. 1. Schematic representation of the microfluidic device used to study AKYPO® and SDS foam flow. Channel depth is $40 \mu \mathrm{m}$. 


\subsection{Experimental protocol}

Entrance pressure above atmospheric pressure was applied for surfactant solution and gas using MCFS ${ }^{\mathrm{TM}}$ EZ 7000 mbar (Fluigent). PEEK (polyetheretherketone) flexible tubes of $59.2 \mathrm{~cm}$ length and $125 \mu \mathrm{m}$ inner diameter were used to connect source pressure to gas and liquid inlets. Pressures considered below, named respectively $P_{\text {gas }}$ for gas and $P_{\text {water }}$ for surfactant solution are upstream applied pressures, above atmospheric pressures. All measurements were carried out when steady flow rate was reached (typically after $30 \mathrm{~s}$ ). In each experiment, gas pressure drop $P_{\text {gas }}$ was kept constant during the flowing (150 mbar or 300 mbar) and the surfactant solution pressure drop $P_{\text {water }}$ varies from $4 P_{\text {gas }}$ to $P_{\text {gas }} / 60$. Each experiment was performed at least twice. Under such applied pressure and with such aspect ratio of the microfluidic device (1200 $\mu \mathrm{m}$ width $W$ and $40 \mu \mathrm{m}$ depth $H$ ), no deformation of the PDMS cell is observed (no defocusing and no loss of sharpness on microchannel images). This is confirmed by the calculation of the deformation criterion $c=W P /(E H)$, defined by Gervais et al. [24], where $P$ is the pressure difference applied on the upper PDMS wall in the observation chamber (the lower glass wall is supposed not to distort) and $E$ is the PDMS Young's modulus $\left(E \approx 10^{6} \mathrm{~Pa}\right)$. In the case of the maximum water pressure difference applied $P_{\text {water }}=1200$ mbar and considering the hydraulic resistance of the microdevice, the pressure difference applied on the PDMS wall $P$ is found to be equal to 3 mbar, leading to a deformation criterion of $8.9710^{-3}$ smaller than one (see calculation in Supplementary material). Accordingly, no deformation is expected at such aspect ratio and such applied pressure.

\subsection{Chemicals}

Foams were generated by co-injection of nitrogen gas and surfactant solution at around $17.33 \mathrm{mM}$ through the cross junction. The surfactants employed are AKYPO ${ }^{\circledR}$ RO $90 \mathrm{VG}$ (nonaoxyethylene oleylether carboxylic acid, R-O- $\left(\mathrm{CH}_{2} \mathrm{CH}_{2} \mathrm{O}\right)_{\mathrm{n}}, \mathrm{R}=\mathrm{C}_{16} / \mathrm{C}_{18}, \mathrm{n}=9$ ) from Kao

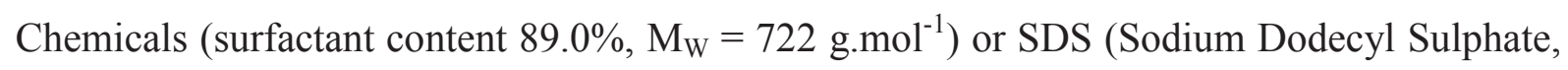
Fischer Scientific, $98 \%, \mathrm{M}_{\mathrm{W}}=288.38 \mathrm{~g} \cdot \mathrm{mol}^{-1}$ ) for the comparative study.

In the case of AKYPO ${ }^{\circledR}$ surfactant solution $\mathrm{pH}$ (initial $\mathrm{pH}$ at 2.90 at $17.33 \mathrm{mM}$ ) was adjusted using either diluted sodium hydroxide solution $(\mathrm{NaOH}$, Titrinorm, $0.1001 \mathrm{~N})$ or nitric acid $\left(\mathrm{HNO}_{3}\right.$, Titrinorm, $\left.1.002 \mathrm{~N}\right)$ to reach a $\mathrm{pH}$ range between 2 and 12. Surface tension of the 
different $A K Y P O{ }^{\circledR}$ solution in function of $\mathrm{pH}$ was obtained from the literature [16] and summarized in Table 1.

For SDS foam flow experiments $(17.33 \mathrm{mM}$ corresponding to $0.5 \% \mathrm{w} / \mathrm{w}), 1$-dodecanol (DOH, Alfa Aeser, $98 \%, \mathrm{M}_{\mathrm{W}}=186.34 \mathrm{~g} \cdot \mathrm{mol}^{-1}$ ) was added to the initial solution to reach different molar ratio SDS/DOH. The solubility of DOH in water is about $1.510^{-2} \mathrm{mM},[15,25]$ which means all the SDS/DOH mixtures solution prepared were above the alcohol solubility. Surface tension of pure SDS solution and SDS/DOH mixture was obtained from the literature and presented in Table 1.

Table 1. Surface tension of AKYPO® solution in function of $\mathrm{pH}$, determined from [16], and surface tension of pure SDS and mixed SDS/DOH solution, determined from [15,25], with $C_{D O H}$.the concentration of dodecanol in millimolar.

\begin{tabular}{cc|cc}
\multicolumn{2}{c|}{ AKYPO } & \multicolumn{2}{c}{ SDS } \\
\hline \hline $\mathrm{pH}$ & $\gamma(\mathrm{mN} / \mathrm{m})$ & $C_{D O H}(\mathrm{mM})$ & $\gamma(\mathrm{mN} / \mathrm{M})$ \\
\hline 2.2 & 31.5 & 0 & $40.5[25] / 36.08[15]$ \\
4 & 32.4 & $>0.015$ & $21[25]$ \\
6 & 34.7 & & \\
8.2 & 36.8 & & \\
10.1 & 37.5 & &
\end{tabular}

\subsection{Image analysis and error estimations}

A fast camera (800 fps) with optical microscopy were used for observations. Image analysis with ImageJ was used for the determination of bubble area $A_{b}$ (see Fig. 5, a), lamella's radius of curvature $R_{C}$ (radius of circle tangent to the lamella, see Fig. 8, b), bubble Feret's diameter $D_{f}$ (bubble diameter along flowing direction, see Fig. 5, b), equivalent diameter $D_{e q}$ (diameter of a disc with the same area as the bubble, $D_{e q}=2 \sqrt{A_{b} / \pi}$, see Fig. 5, c), areal bubble number density $d$ (number of bubbles per surface unit in bubbles $/ \mathrm{mm}^{2}$ ), topology number $T$ (number of bubble rows across the channel width), and areal liquid fraction $\varphi$ (ratio between the number of black pixels and the total pixel number inside the microchannel). Each analysis were realised from 50 to more than 1000 bubbles depending on the foam flow regime considered. The image processing was carried out using ImageJ software package. Brightness and contrast of each image were first adjusted and then all the images were automatically thresholded in order to clearly separate the black network of edges or Plateau border and film 
from white bubbles. A classical skeletonization method was then used when needed to separate bubbles from each other. This image processing is robust and thanks tohigh contrastedpictures no variation of the quantities measured is observed when varying manually the threshold.

Standard errors $E$ in measured foam parameters were estimated using the standard deviation method based on the number of analysed bubbles $N$ and standard deviation $S D: E=S D / \sqrt{N}$. In the bubbly liquid regime, where bubbles are spheroids and well separated from one another, there is a discrepancy between the measured areal liquid fraction and the real volume liquid fraction which vanishes in the very dry foam regime where bubbles are squashed together. This difference between the measured areal liquid fraction and the real volume liquid fraction can be estimated by calculating real bubble volume and equivalent bubble volume and contributes to a systematic error on bubble volume $E_{V}$ in addition to the standard error $E$. Considering a bubble squeezed between two planes (see Fig. 2),[19] it can be divided into two volumes $V_{1}$ and $V_{2}$ that represent a cylinder of radius $R$ and a piece of torus of minor radius $H / 2$ with $H$ the height of the microchannel equal to $40 \mu \mathrm{m}$.
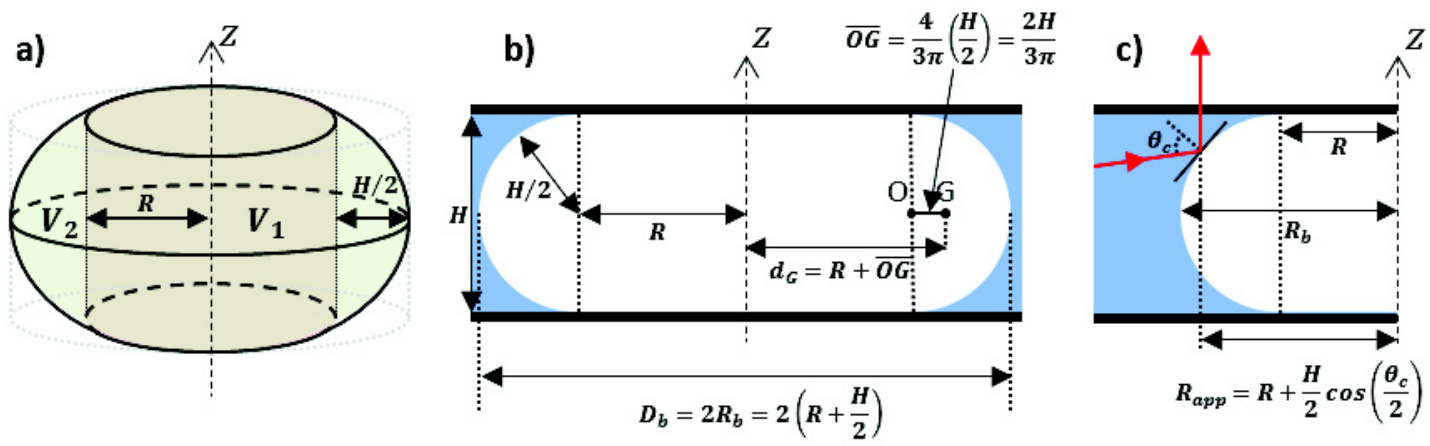

Fig. 2. Bubble shape compressed between two plates in the bubbly liquid regime. (a) 3D representation of spherical compressed bubble. (b) $2 \mathrm{D}$ bubble cross section. $\boldsymbol{V}_{\mathbf{1}}$ and $\boldsymbol{V}_{\mathbf{2}}$ are the cylinder and piece of torus volume respectively, $\boldsymbol{R}$ is the cylinder radius, $\boldsymbol{H}$ the microchannel height, $\boldsymbol{D}_{\boldsymbol{b}}$ the real bubble diameter and $\boldsymbol{d}_{\boldsymbol{G}}$ the distance between the half circle gravity center $\mathrm{G}$ and the $\mathrm{z}$ rotation axis. The centroid-to-cylinder distance $\overline{O G}$ is obtained by using a surface integral in polar coordinates on the half circle. (c) Scheme of a half-compressed bubble illuminated in transmission by a diffuse extended light source where $\boldsymbol{R}_{\boldsymbol{a p} \boldsymbol{p}}$ is the apparent bubble radius and $\boldsymbol{\theta}_{\boldsymbol{c}}$ is the critical angle of total light reflexion (i.e. $48.8^{\circ}$ ).

The volume of the cylinder $V_{1}$ can be calculated as follows:

$$
V_{1}=\pi R^{2} H
$$


The volume of the piece of torus $V_{2}$ can be calculated using the Pappus-Guldinus theorem [26] which states that the volume of a solid of revolution generated by rotating a plane figure (half disc of radius $H / 2$ ) about an external axis $\mathrm{z}$ is equal to the product of the area of the plane figure 2 and the distance travelled by its geometric centroid $2 \pi d_{G}$. The volume $V_{2}$ is then calculated as follows:

$$
\begin{gathered}
V_{2}=A \times 2 \pi d_{G}=\frac{1}{2} \pi\left(\frac{H}{2}\right)^{2} \times 2 \pi\left(R+\frac{2 H}{3 \pi}\right) \\
V_{2}=\pi^{2} \frac{H^{2}}{4}\left(R+\frac{2 H}{3 \pi}\right)
\end{gathered}
$$

The real bubble volume $V_{b}$ of radius $R_{b}=R+H / 2$ is the sum of $V_{1}$ and $V_{2}$ and is equal to:

$$
V_{b}=V_{1}+V_{2}=\pi R^{2} H+\pi^{2} \frac{H^{2}}{4}\left(R+\frac{2 H}{3 \pi}\right)
$$

It can then be calculated by replacing $R$ by $R_{b}-H / 2 . R_{b}$ is determined from the apparent measured radius $R_{a p p}$. When a bubble is illuminated in transmission by a diffuse extended light source, its image is a dark ring with a radius corresponding to the apparent bubble radius $R_{a p p}$ that can be calculated as follows:[27]

$$
R_{a p p}=R+\frac{H}{2} \cos \left(\theta_{c} / 2\right)
$$

where $\theta_{c}$ is the critical angle of total light reflexion and is equal for water/air interface to $48.8^{\circ}$ (see Fig.2, c). In the case of a directed light source, by contrast, as is usually done for optical microscopy, the apparent radius $R_{a p p}$ can be taken to be equal to the real bubble radius $R_{b}$

The equivalent bubble volume $V_{a p p}$ used for the calculation of the areal liquid fraction corresponds to the volume of a cylinder with a radius $R_{a p p}$ and a height $H$ that is obtained from the projection of the dark ring on the whole height of the microchannel and is calculated as follows:

$$
V_{a p p}=\pi R_{a p p}^{2} H
$$


The two volume $V_{b}$ and $V_{a p p}$ can then be calculated from experimental apparent radius $R_{a p p}$ and microchannel $H$ and used to estimate the systematic volume error $E_{V}$ using the following expression:

$$
E_{V}=\frac{\left|V_{a p p}-V_{b}\right|}{V_{b}}
$$

The highest volume error on bubble is obtained in the wet limit regime where bubbles are the smallest $\left(R_{a p p}=39 \mu \mathrm{m}\right)$ and is equal to $24.2 \%$ per bubble. This error decreases with increasing bubble radius to $2.19 \%$ for the biggest bubble $\left(R_{a p p}=397 \mu \mathrm{m}\right)$ at $P_{\text {gas }} / P_{\text {water }}=1.15$. For a given foam of volume $V_{\text {tot }}$ and composed of $N$ bubbles, the gas fraction is defined as the ratio between the total gas volume $N V_{b}$ (volume occupied by the $N$ bubbles) divided by the foam volume $V_{\text {tot }}$. [1] The systematic relative error on gas liquid fraction $E_{\varphi_{g a s}}$ between the measured areal gas fraction $\varphi_{g a s}=N V_{a p p} / V_{t o t}$ and the real volume gas fraction $\varphi_{\text {gas }}^{r}=N V_{b} / V_{\text {tot }}$ can then be estimated as follows:

$$
E_{\varphi_{\text {gas }}}=\frac{\left|\varphi_{\text {gas }}^{r}-\varphi_{\text {gas }}\right|}{\varphi_{\text {gas }}^{r}}=E_{V}
$$

The relative error on the gas fraction $E_{\varphi_{g a s}}$ is thus equal to the systematic bubble volume error $E_{V}$. The liquid fraction of a foam $\varphi$ is finally defined as:

$$
\varphi=1-\varphi_{\text {gas }}
$$

This leads to an absolute error on the measured areal liquid fraction $\varphi$ between around $7 \%$ for the wettest foam $(\varphi=82 \%)$ and $2 \%$ for the driest one $(\varphi=5.23 \%)$. Therefore the measured areal liquid fraction $\varphi$ can be considered as a good approximation to estimate the real volume liquid fraction of the foam inside the microchannel.

The error on pressure ratio was estimated using the law of propagation of uncertainty considering an error of \pm 10 mbar on water pressure $P_{\text {water }}$. This explains the increasing error on pressure ratio with decreasing water pressure.

\section{Results and discussion}

\subsection{AKYPO ${ }^{\circledR}$ foam flow.}


Foam flow experiments with $A K Y P O{ }^{\circledR}$ solution at different pressure ratio and different $\mathrm{pH}$ with gas pressure of 150 mbar were first performed. As detailed in Quennouz et al. [11] diphasic flow regime is always obtained due to applied gas pressure exceeding Laplace pressure $\Delta P_{L}$ at the cross junction $\left(\Delta P_{L}=31 \mathrm{mbar}\right.$ for non-wetting conditions, $60 \mu \mathrm{m}$ in width and $40 \mu \mathrm{m}$ in depth channel and for $37.5 \mathrm{mN} / \mathrm{m}$ in case of $\mathrm{pH} 10.1$ ). These experiments allowed to obtain a phase diagram presented in Fig. 3 that shows the morphology of foam for each physicochemical conditions. This phase diagram clearly presents 5 different foam morphology regime already described in the literature:[11,28]

- Bubbly liquid $\left(P_{\text {gas }} / P_{\text {water }}<0.6\right)$. The bubbles flow freely with no interactions between them. A sub-regime can sometimes be observed within this regime, called dripping, in which the bubbles are formed one by one.

- Wet foam $\left(0.6<P_{\text {gas }} / P_{\text {water }}<0.9\right)$. Bubbles begin to interact with one another and an overall movement is observed. This regime can be recognized from the previous one by the liquid fraction of the dispersion. The inter-bubble film is thick enough to limit gas diffusion and hence ripening.[19]

- Polyhedral foam $\left(0.9<P_{\text {gas }} / P_{\text {water }}<1.1\right)$. The foam becomes very dry and the bubbles interact strongly with each other. In this regime, staircase (ex: $\mathrm{pH}=10.3$, $\left.P_{\text {gas }} / P_{\text {water }}=1.05\right)$ or double-staircase $\left(\mathrm{ex}: \mathrm{pH}=4.30, P_{\text {gas }} / P_{\text {water }}=0.95\right)$ structure are sometimes observed. $[7,15]$

- Bamboo foam $\left(1.15<P_{\text {gas }} / P_{\text {water }}\right)$. The bubble size becomes close to the channel width and the foam flows in the form of lamellae. The gas can diffuse easily between the bubbles without necessarily producing coalescence and coarsening.[29]

- Corner-flow or stratified regime $\left(1.15<P_{\text {gas }} / P_{\text {water }}\right)$. The liquid flows mainly into the corners of the channel and to the wall as wetting films. 


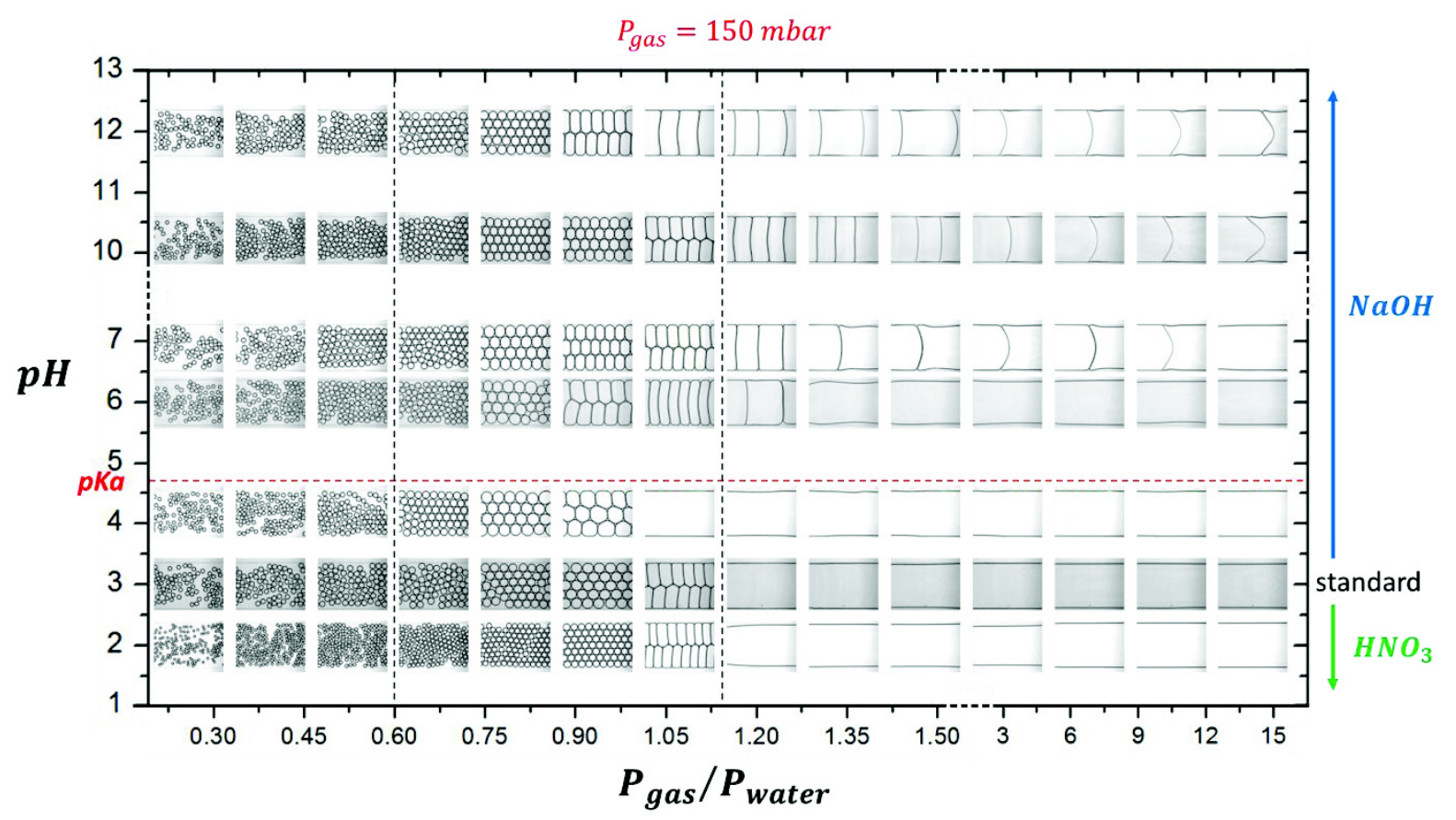

Fig. 3. Foam phase diagram of $A K Y P O 囚$ solution $(17.33 \mathrm{mM})$ as function of pressure ratio $\boldsymbol{P}_{\text {gas }} / \boldsymbol{P}_{\text {water }}$ and $\mathrm{pH}$ for a gas pressure $\boldsymbol{P}_{\text {gas }}=150$ mbar.

These different regimes are characterized by topological transitions, i.e. by modification of the number of rows in the foam across the channel width $T$. These transitions are highlighted by vertical dashed lines. Furthermore, the horizontal dashed line that represents the apparent $\mathrm{pK}_{\mathrm{a}}$ value of $\mathrm{AKYPO}{ }^{\circledR}$ at $17.33 \mathrm{mM}$ (determined by $\mathrm{pH}$ titration) divides the phase diagram in two parts : the lamellae preponderance domain $\left(\mathrm{pH}>\mathrm{pK}_{\mathrm{a}}\right)$ and the wetting films preponderant domain $\left(\mathrm{pH}<\mathrm{pK}_{\mathrm{a}}\right)$.

For each experiment, quantitative physicochemical data were obtained by image analysis with ImageJ. The images are processed by a conventional thresholding and segmentation protocol to separate the different bubbles. Using these processed images, it is thus possible to examine several quantitative magnitudes: bubble area $A_{b}$ (see Fig. 5, a), Feret's $D_{f}$ (bubble diameter along flowing direction, see Fig. 5, b) and equivalent $D_{e q}$ diameters (diameter of a disc with the same area as the bubble, $D_{e q}=2 \sqrt{A_{b} / \pi}$, see Fig. 5, c), topology number $T$ (number of bubble rows across the channel width), liquid fraction $\varphi$ (ratio between the number of black pixels and the total pixel number inside the microchannel) and bubble number density $d$ (number of bubble per surface unit). However, it must be remembered that liquid is only observed in the equivalent 2D-Plateau borders (junction between three liquid films: two wetting films on channel wall and one perpendicular between two bubbles). The high optical index ratio between the gas and the liquid, and the good configuration used allowed to 
observe well defined bubble cell boundaries and Plateau border thickness which is favourable for our quantitative analysis. The results for the determination of the bubble area $A_{b}$ are presented in Fig. 4. Quantitative analysis stops when bubble size becomes higher than the observation window $\left(P_{\text {gas }} / P_{\text {water }}>1.2\right)$.

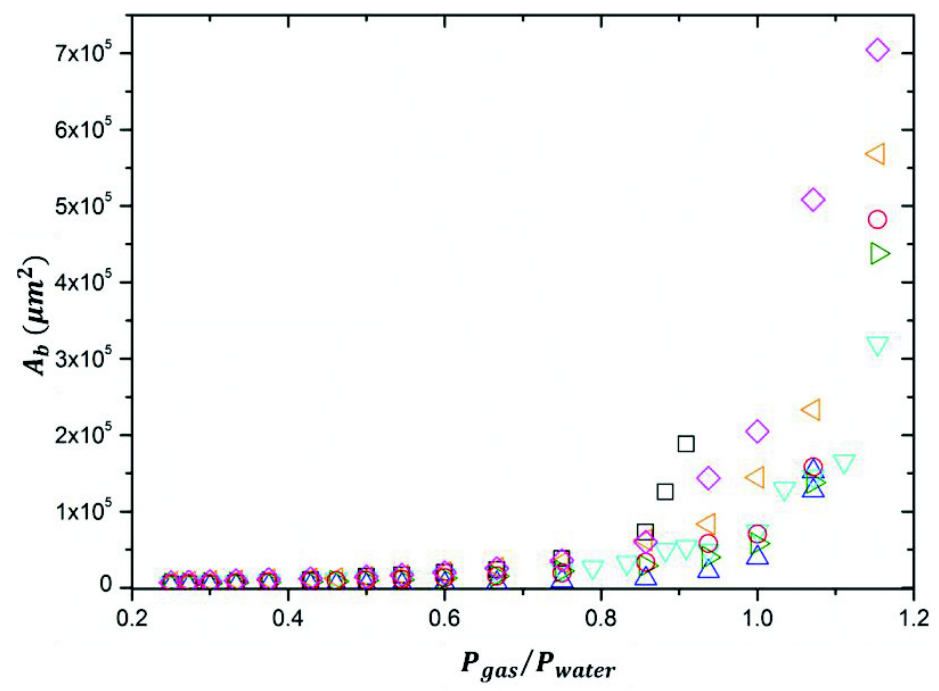

Fig. 4. Bubble area determined by image analysis as function of fluid pressure ratio at different $\mathrm{pH}: 1.99(\triangle)$, $2.89(\nabla), 4.30(\square), 6.13(\triangleleft), 6.73(\triangleright), 10.3(\bigcirc)$ and $12.0(\diamond)$.

This shows that, by increasing the pressure ratio the bubble size increases. The largest bubble size result from the bubble production and not to rupture, related to pinch-off or constriction, occurring during the transport. However, no significant effect of $\mathrm{pH}$ on bubble area can be highlighted because all the variations are included in the pressure ratio error bar (see Fig. 5, a). This last observation is verified for all of the different physical quantities determined by image analysis. In the following, only the averaged values, presented on Fig. 5 will be discussed.

The geometrical parameters, $A_{b}, D_{f}$ and $D_{e q}$ show the same trend (see Fig. 5, a, b and $\mathbf{c})$. The bubble size increases when the ratio $P_{\text {gas }} / P_{\text {water }}$ increases as previously observed with SDS foam.[11,28] The comparison between the Feret's diameter $D_{f}$ and the equivalent diameter underlines that, under a pressure ratio of 0.8 , bubbles are quite spherical (more precisely cylindrical due to the confinement) and becomes polyhedral after this value which is confirmed by the capture picture on Fig. 3. After this value, bubbles become polyhedral that 
corresponds to the beginning of the dry foam regime $(\varphi \approx 0.3$ on Fig. 5, d).
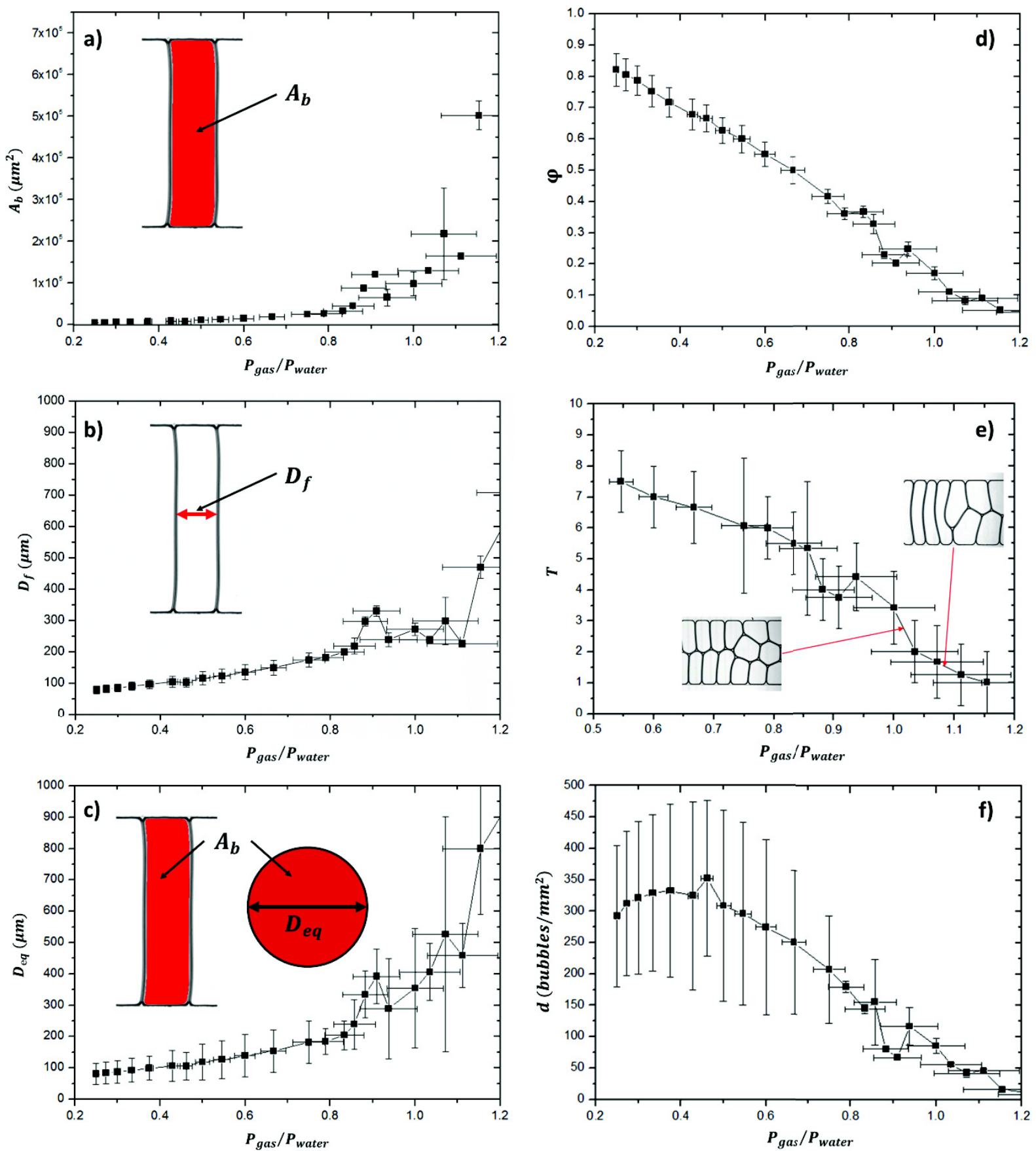

Fig. 5. Average physical parameters of $A K Y P O ®$ foam at $17.33 \mathrm{mM}$ with 150 mbar gas pressure as function of pressure ratio: (a) Bubble area $\boldsymbol{A}_{\boldsymbol{b}}$, (b) Feret's diameter $\boldsymbol{D}_{\boldsymbol{f}}$, (c) equivalent diameter $\boldsymbol{D}_{\boldsymbol{e q}}$, (d) liquid fraction $\boldsymbol{\varphi}$ (only the standard error $E$ is represented and not the systematic error $E_{\varphi}$ ), (e) topology $\boldsymbol{T}$ and (f) bubble number density $\boldsymbol{d}$. Black lines are guide to the eye.

The topology number $T$ (see Fig. 5,e) which represents the number of bubble rows is defined from the beginning of bubble interaction (wet foam) to lamellae flow. This corresponds to a pressure ratio of 0.55 with a topology number of around 7 . Then, due to the 
increasing bubble size (see Fig. 5, a, c and e) the number of rows decreases until it reaches 1 that corresponds to lamellae flow. The transition between three rows and two rows foam and two rows and one row foam occurs by $\mathrm{T} 1$ transition (bubble neighbour switching) sometimes called T1-wave (see inserts on Fig. 5, d). [30,31] After these two transitions, foam lamellae are not stable enough and break down depending on $\mathrm{pH}$. The bubble number density curve (see Fig. 5, f) gives also interesting informations on foam transition when comparing with Fig. 5, a even if it is difficult to state on the phenomenon with confidence due to the large error bars. The bubble number density increases until it reaches a local maximum at around $P_{\text {gas }} / P_{\text {water }} \approx 0.4$ that could correspond to the beginning of bubble area increase. Then bubble number density decreases accompanied with bubbles area growth until no bubbles are formed. This means that, by increasing gas pressure the bubble number density increases until bubbles become close enough to be in contact with each other and then they become to grow through coalescence.

a)
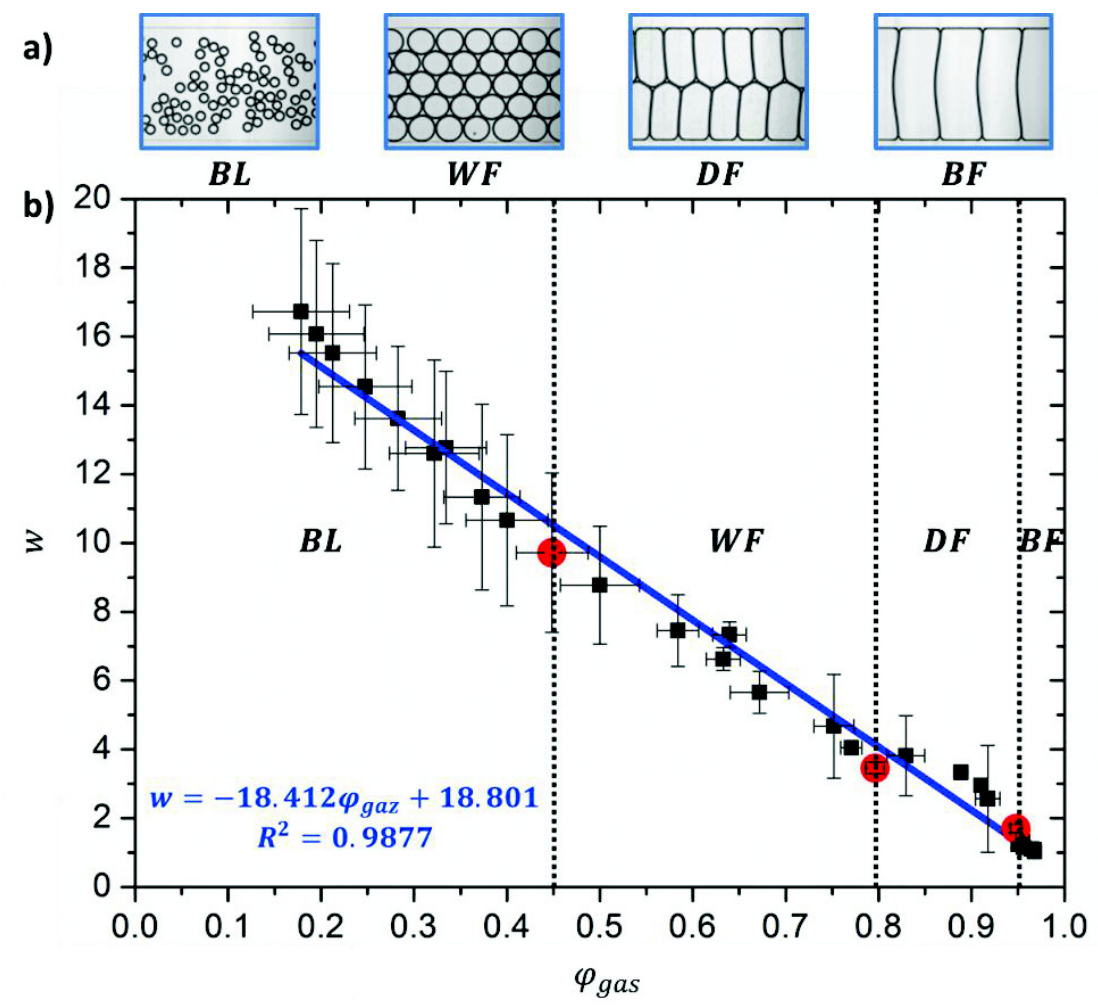

Fig. 6. a) Four main bubble packing observed in the microdevice channel. From left to right: bubbly liquid $(B L)$, wet foam $(W F)$, dry foam $(D F)$ and bamboo foam $(B F)$. b) Dimensionless channel width $w=W / \sqrt{A_{b}}$ as function of areal gas fraction $\varphi_{\text {gas }}=1-\varphi$. The (blue) straight line represents the linear regression with a slope of -18.412, an intercept of 18.801 and a correlation coefficient $R^{2}$ equal to 0.9877 ., 
In order to compare the structures and the topology transitions observed to previous works, the dimensionless channel width $w=W / \sqrt{A_{b}}$ can be considered as suggested by Claussen et al. [32]. Such a ratio, used by Claussen et al. to discuss emulsions topology can help to quantify phase diagram for a global view in different geometries and for different systems [30,33]. $w$ is plotted as function of areal gas fraction $\varphi_{\text {gas }}=1-\varphi$ (see Fig. 6). The dimensionless channel width decreases linearly with increasing areal gas fraction related to the increase of bubble area. Similar results were already obtained for foam made with dishwashing detergent (mainly SDS) [30,33] in a narrower channel. Fig. 6, b is divided in four region that represent the four main bubble packing observed in the microdevice which correspond to the different morphology regime (see Fig. 6, a): bubbly liquid ( $B L$, sometimes referred to as bubbly flow or loose assembly), wet foam ( $W F$, sometimes referred to as alternate foam), dry foam ( $D F$, sometimes referred to as staircase packing) and bamboo foam ( $B F$, sometimes referred to as bamboo packing). [30-32] A good correlation is obtained between the topology transitions observed in Fig. 6, b and the packing diagram of monodisperse emulsion droplets in a rectangular channel geometry based on a droplet surface energy model described by Claussen et al. [32], and notably in the bamboo foam region at high areal gas fraction and low dimensional width. However, no zigzag packing described by Claussen et al. [32] nor bidisperse bubbles flow described by Raven et al. [30,33] were observed in the present geometry because they correspond to lower dimensionless width value (narrower channel). These results confirm the assumption that foam packing mainly depends on injection parameters and obviously to the channel geometry and bubble formation.

This first set of results reveals that, foam morphology depends only on the fluid injection parameters (pressure ratio) and channel geometry and is comparatively independent of $\mathrm{pH}$. This last parameter plays a significant role on lamella stability in the case of a bamboo foam. By increasing $\mathrm{pH}$, lamellae can be generated at high pressure ratio whereas in acidic conditions no lamellae are formed (see Fig. 3). It can be explained by the pH sensitivity of AKYPO ${ }^{\circledR}$ surfactant that bears a carboxylic acid function. Previous studies have pointed out the crucial impact of $\mathrm{pH}$ on AKYPO ${ }^{\circledR}$ micelle and foam.[16,34] In one hand, Small angle neutron scattering (SANS) on steady state AKYPO ${ }^{\circledR}$ foam at $0.5 \mathrm{mM}$ had demonstrated that, by increasing $\mathrm{pH}$ foam film thickness decreased from more than $1000 \AA$ at $\mathrm{pH} 2$ to $380 \AA$ at $\mathrm{pH}$ 8. Furthermore surface tension and zeta potential measurements on AKYPO ${ }^{\circledR}$ solution had showed that by decreasing $\mathrm{pH}$, surface charge and critical micelle concentration decrease, favouring liquid-air coverage, by increasing surfactant surface excess at the liquid-air 
interface, and surfactant-surfactant interactions. These observations led to the conclusion that, foam film thickness is related to the cohesive energy of the surfactant layer adsorbed at the liquid-air interface.[16] By decreasing $\mathrm{pH}$, cohesive energy increases leading to thicker film: the increasing in cohesive energy leads to a higher resistance to liquid flow inside the foam film, i.e. drainage, which induces a Poiseuille like flow. In another hand, SANS on AKYPO® micelles had also demonstrated that, by increasing $\mathrm{pH}$ micelle volume decreases from $354.2 \mathrm{~nm}^{3}$ at $\mathrm{pH} 2$ to $121.5 \mathrm{~nm}^{3}$ at $\mathrm{pH} 8$ for a surfactant concentration of $0.5 \mathrm{mM}$.[34] In our case of flowing lamellae, the stability of foam seems to be due to the presence of the carboxylate form of the surfactant. This preponderant form at $\mathrm{pH} 12$ induces electrostatic repulsion that is known to stabilize foam thanks to the DLVO theory[17] by preventing the rupture of the film (transverse interactions) even if films are thicker than in acidic conditions, and seems to confer to the film a sufficient resistance to flow by giving the appropriate cohesive forces between surfactants at the liquid-air interface (lateral interactions). The information on micelle size suggests that lamella stability is not linked to a micelle stratification phenomenon[35] but one can imagine that smaller micelles could migrate more rapidly to the liquid-air interface during the film generation and counterbalance the surfacetension gradient more efficiently than the bigger ones which can be seen as a more efficient interface healing during the formation ( $c f$. Marangoni effect). Lastly, another hypothesis could be that, surfactant in carboxylate form leads to a low value of the surface expansion modulus which facilitates the surface stretching during lamellae generation whereas in its acidic form the surface provides a solid behaviour (high-surface coverage and high expansion modulus) which makes it easy to break.[1]

The effect of pressure amplitude on 2D-foam generation and morphology was investigated by changing the gas pressure to 300 mbar. The corresponding foam phase diagram is presented in Fig. 7. It clearly presents the 5 different foam morphology regimes previously described at 150 mbar gas pressure. However the second transition regime frontier (vertical dashed line) is shifted to lower pressure ratio values and the foam lamellae domain is reduced and begin earlier partly due to an increase in bubble size with gas pressure increase that can be seen by comparing Fig. 3 and Fig. 7. Moreover, the effect of pH on lamella stability is still observed. A wetting film (or equivalent 2D Plateau border) thinning in the corners of the microchannelis also observed for high pressure ratio and $\mathrm{pH}$. As pressure ratio increases, the remaining liquid left decreases on the small wall of the microchannel $(40 \mu \mathrm{m})$ as it can be seen on Fig. 7, and by comparing with Fig. 3. This phenomenon cannot be observed on the large walls $(1200 \mu \mathrm{m})$ of the microchannel with this experimental setup but 
the same behaviour is expected for various reasons (drainage, convection, relatively less water phase volume is injected, etc.). These observations are in agreement with Bretherton's work. [36]

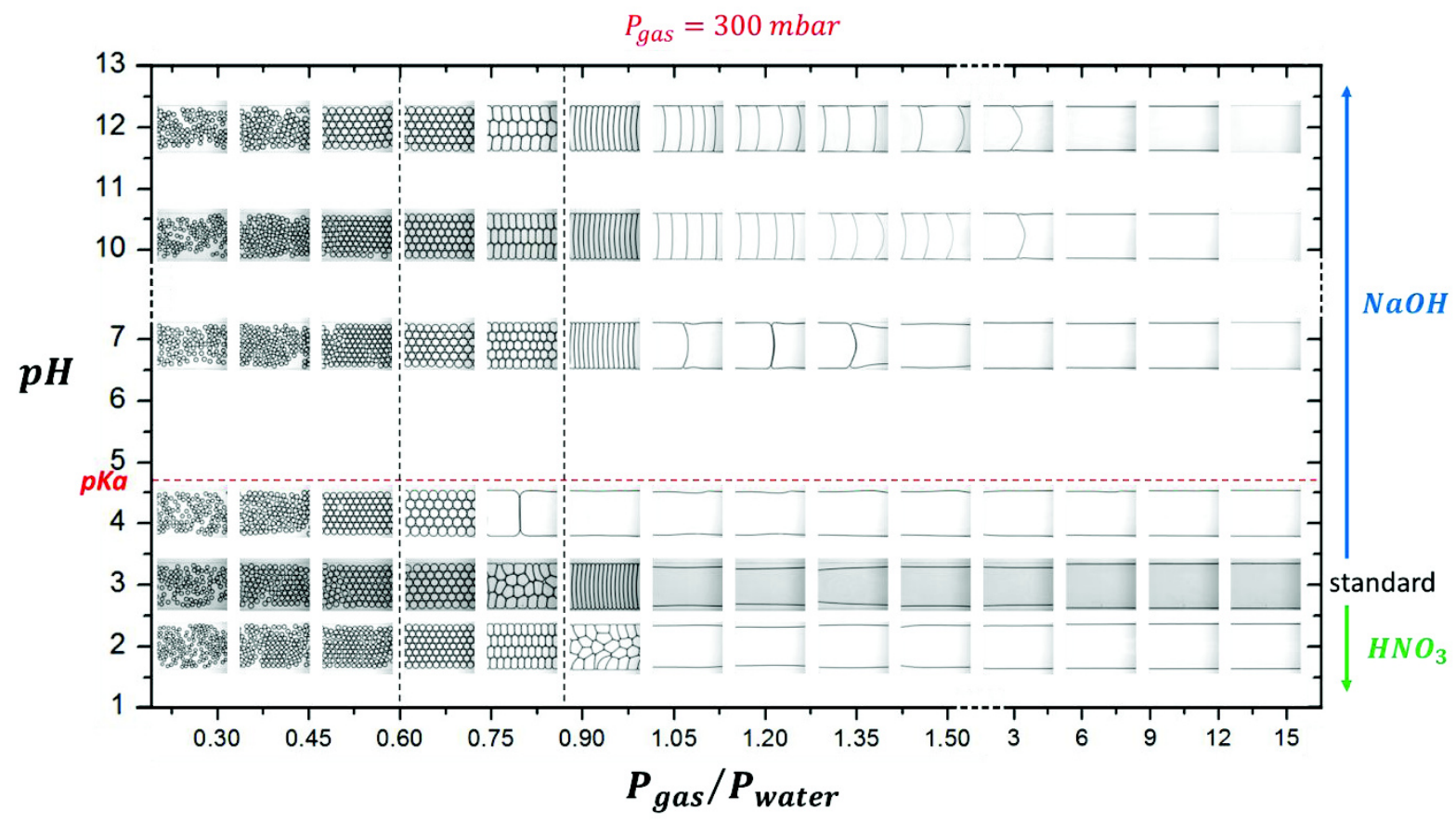

Fig. 7. Foam phase diagram of $A K Y P O ®$ solution $(17,33 \mathrm{mM})$ as function of pressure ratio $\boldsymbol{P}_{\text {gas }} / \boldsymbol{P}_{\text {water }}$ and $\mathrm{pH}$ for a gas pressure $\boldsymbol{P}_{\text {gas }}=300$ mbar.

This shift in lamellae formation domain may be induced by the increase in gas pressure value. Previous work on flow-focusing geometry with commercial dishwashing detergent (Dreft) and nitrogen had demonstrated the influence of gas pressure on bubble flowrate and foam morphology.[33] By increasing the gas pressure, bubble flow rate increase and a rearrangement of bubbles from two bubble rows to one is observed associated with a gas pressure drop. This phenomenon is highlighted by the comparison between Fig. 3 and Fig. 7 which clearly shows this transition morphology induced by increasing gas pressure.

In addition, the absence of lamellae at high pressure ratio, even at high $\mathrm{pH}$ (12.0), can be explained by the generation dynamics. The lamella formation (expansion) is too quick compared to the adsorption dynamic of the surfactant which leads to an unstable lamellae and thus to a reduction of their domain.[1] Further dedicated study is require in order to better understand this phenomenon considering AKYPO ${ }^{\circledR}$ diffusion coefficients (around $\left.2.4 \times 10^{-9} \mathrm{~m}^{2} / \mathrm{s}\right)[15]$ and the bubble formation time at high pressure ratio.

Finally, these two different experiments have shown that, the foam morphology in the microfluidic device is mainly controlled by the pressure ratio and gas pressure value whereas 
the stability of the foam lamellae depends on surfactant properties that can be tuned for example by $\mathrm{pH}$.

\subsection{Comparison between $A K Y P O{ }^{\circledR}$ and SDS 2D-foams.}

Foam flow experiment with SDS at $17.33 \mathrm{mM}$ was performed with a gas pressure of 150 mbar. Dodecanol (DOH) was used to change the interface behaviour of SDS. DOH is known to form mixed monolayers with SDS at the air-water interface increasing the surface viscosity.[37,38] The concentration ratio $C_{D O H} / C_{S D S}$ vary from 0 to 1 and for high dodecanol concentration precipitates are formed (see Fig. 8, b) due to low dodecanol solubility and the solution becomes opalescent (the effect of precipitates on foam stability was no studied here). [39] The corresponding phase diagram is presented in Fig. 8, a.

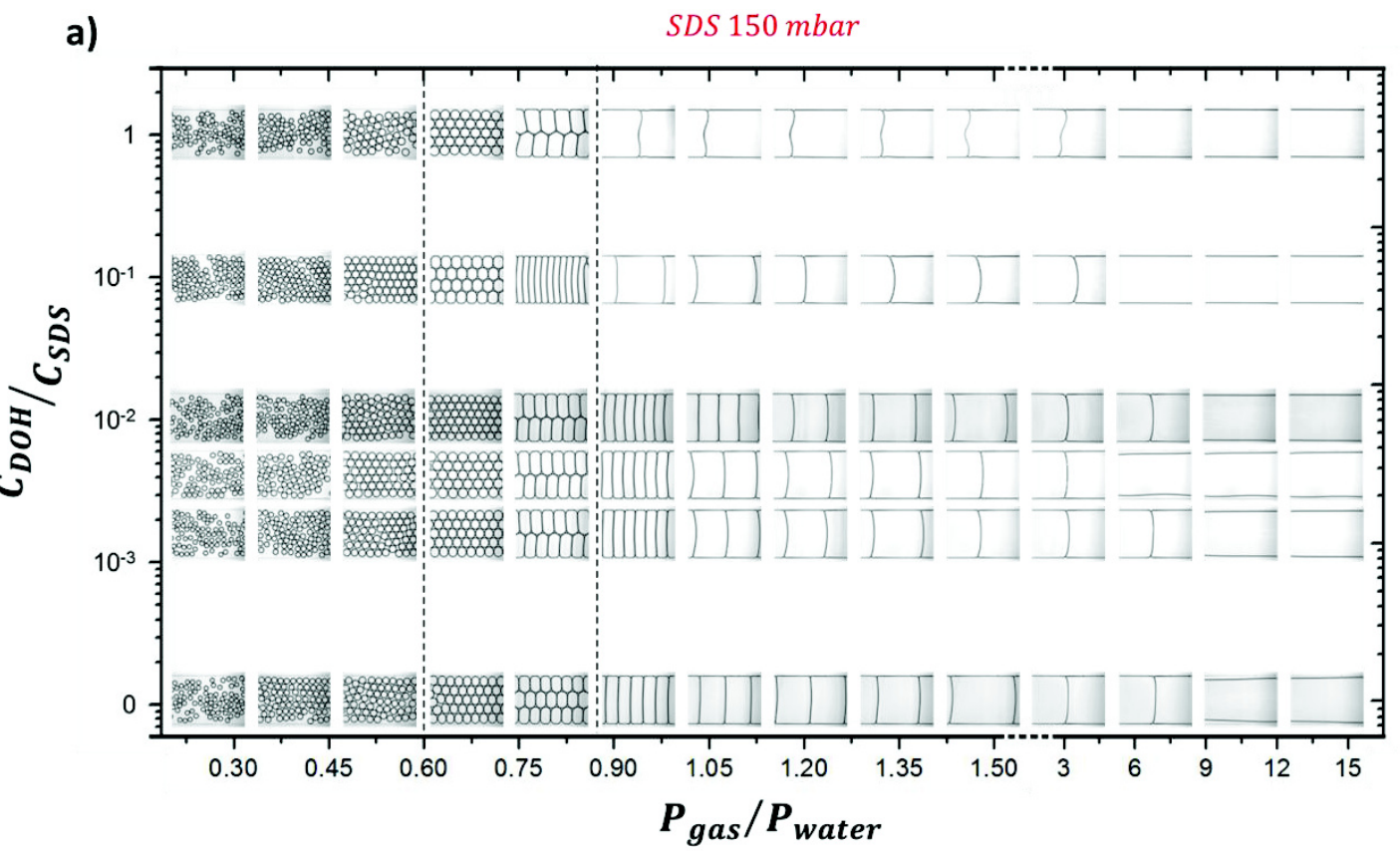

b)

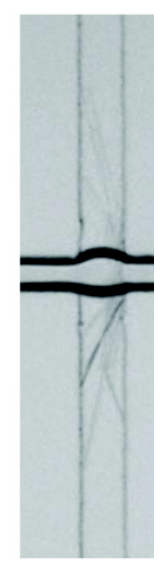

Fig. 8. (a) Foam phase diagram of SDS solution $(17,33 \mathrm{mM})$ as function of pressure ratio $\boldsymbol{P}_{\text {gas }} / \boldsymbol{P}_{\boldsymbol{w a t e r}}$ and concentration ratio $\boldsymbol{C}_{\boldsymbol{D O H}} / \boldsymbol{C}_{\boldsymbol{S D S} \text { S }}$ for a gas pressure $\boldsymbol{P}_{\boldsymbol{g a s}}=150$ mbar. (b) Picture of the cross-junction showing dodecanol precipitates for $\boldsymbol{C}_{\boldsymbol{D O H}} / \boldsymbol{C}_{\boldsymbol{S D S}}=1$.

As previously observed with $\mathrm{AKYPO}{ }^{\circledR}$, the phase diagram presents the 5 different foam morphology regimes. Nevertheless, dodecanol seems to have a low impact on lamellae stability because it does not alter the lamellae preponderant domain when its concentration increases (lamellae always formed at $P_{\text {gas }} / P_{\text {water }}=3$ ). Furthermore, for high dodecanol concentration, lamellae shape is altered to a double bump shape. This can be explain by the low water solubility of dodecanol, around $0.02 \mathrm{mM}\left(\approx 4 \mathrm{mg} \cdot \mathrm{L}^{-1}\right)[25]$ and the formation of 
solid needle-shape precipitates observed in the flow-focusing channel (see Fig. 8, b). Precipitates adsorb to the interface and are transport by the lamella into the Plateau border on channel wall. This centered double bump shape is mainly due to the geometry of the microchannel device, the generation process and the pinning of foam films due to the deposited precipitates. They accumulate in the injecting channel of $2700 \mu \mathrm{m}$ length (see Fig. 8, b) at the entrance and are driven by freshly formed lamella which undergoes a kind of lamellar division process[40] when entering in the foam observation chamber.
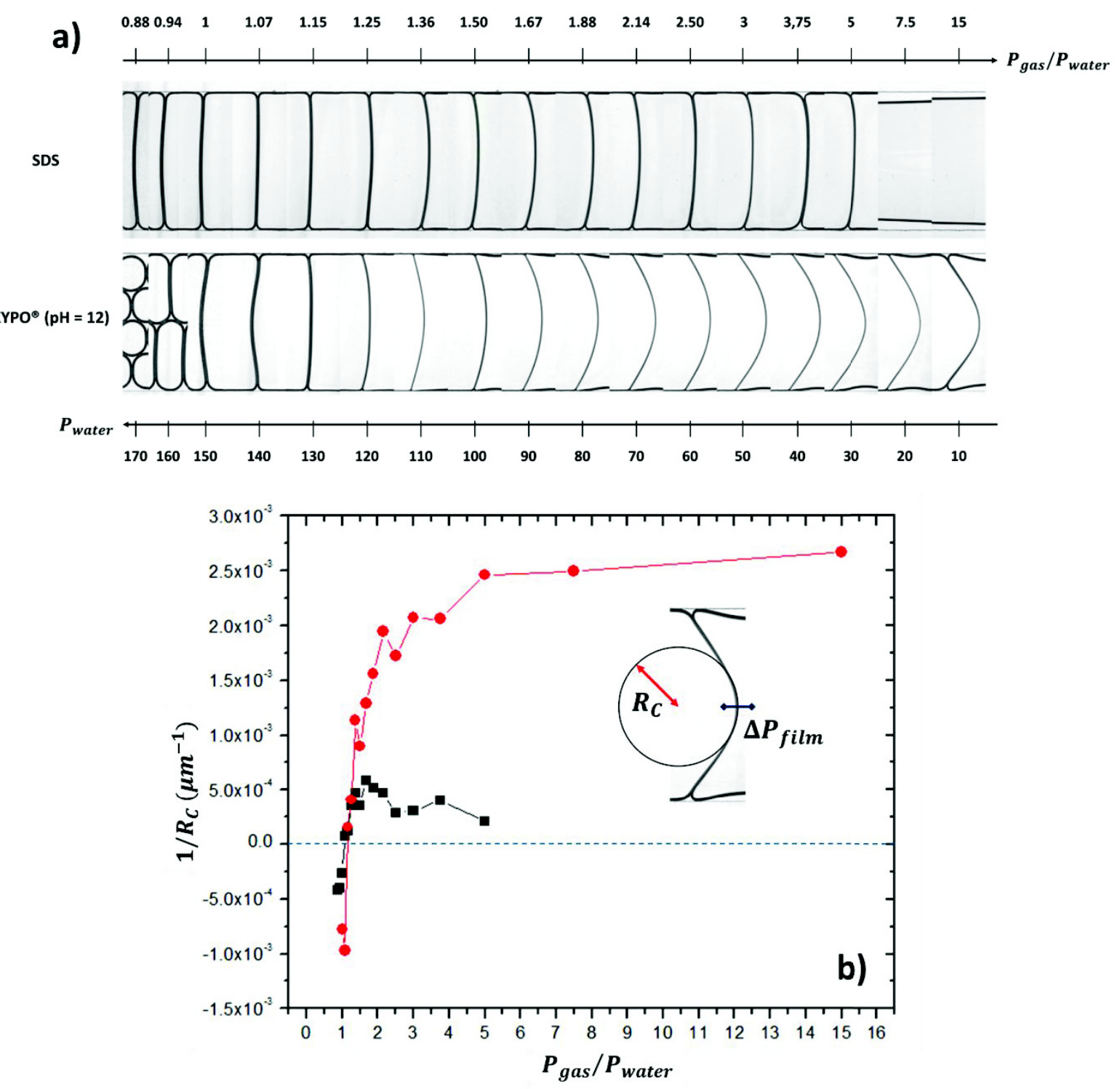

Fig. 9. Comparison of lamellae shape between pure SDS solution (ם) and AKYPO® solution (•) at pH 12, for a $17.33 \mathrm{mM}$ surfactant concentration and 150 mbar gas pressure. (a) lamellae pictures as function of pressure ratio/water pressure and (b) lamellae curvature 
An interesting aspect of the comparison between SDS and AKYPO ${ }^{\circledR}$ foam is the difference in the lamellae shape/radius of curvature with the increasing pressure ratio. Lamellae pictures on Fig. 9, a clearly highlights the different behaviour of foam film under varying pressure ratio for the two surfactants. In the case of SDS bamboo foam, for low pressure ratio, lamellae are curved backward. By increasing the pressure ratio, lamellae become flat (between 1 and 1.07) and then are curved forward until they breakdown for high pressure ratio. As it can be seen, foam lamella curvature radius is only slightly affected by the increasing pressure ratio and fluctuates around $2500 \mu \mathrm{m}$. In the case of AKYPO ${ }^{\circledR}$ foam, the lamellae also provide a curvature direction change at pressure ratio around 1.07. Nevertheless, by increasing the pressure ratio, foam lamellae are strongly deformed that indicates a pressure rising on the left side of the foam film.

To point out these differences, algebraic curvatures $1 / R_{C}$ of SDS and AKYPO ${ }^{\circledR}$ foam measured with the Three Point Circular ROI plugin of ImageJ are presented in Fig. 9, b. Curvatures were measured in the center of the lamellae (see picture in Fig. 9, b) excepted for difficult cases, for example at the curvature reversal, where the curvature was considered equal to zero. It is clearly seen that, SDS curvature is weakly modified with pressure ratio whereas AKYPO ${ }^{B}$ curvature increase continuously until it reaches a plateau at around $2.6 \times 10^{-4} \mu \mathrm{m}^{-1}$. As a first approximation, the pressure gradient can be estimated using the Young-Laplace equation even if the lamellae are non-equilibrated:[41]

$$
\Delta P=\gamma\left(\frac{1}{R_{1}}+\frac{1}{R_{2}}\right)
$$

where $\Delta P$ is the pressure difference of both side of an interface, $\gamma$ is the surface tension and $\frac{1}{R_{1}}$ and $\frac{1}{R_{2}}$ are two principal curvatures. Applying twice the Young-Laplace equation to a foam film (two liquid/gas interfaces), excluding Plateau borders on the upper and lower plates of the microfluidic device, the following equation is obtained:

$$
\Delta P_{f i l m}=2 \gamma\left(\frac{1}{R_{1}}+\frac{1}{R_{2}}\right)
$$

where $\Delta P_{\text {film }}$ is the pressure difference on both sides of the foam lamella. The first principal radius of curvature corresponds to the radius along the confining plates, whereas the second principal radius of curvature may vary between the cell depth $H / 2(20 \mu \mathrm{m})$ and infinity. Such curvatures correspond to pressure drops respectively of $18 \mathrm{mbar}$ and 0 mbar for a 36.08 $\mathrm{mN} \cdot \mathrm{m}^{-1}$ (see below). This second curvature could not be measured in the present experimental configuration, but the first one is partially characterized quantified through the radius of curvature along the confining plates $R_{c}$ (view from above the top plate, see Fig. 9). This 
curvature radius $R_{C}$ can be related to the pressure difference of both side of the foam film $\Delta P_{\text {film }}$ and a viscous drag force $\zeta v_{\perp}$ through the viscous froth model as follows [41,42]:

$$
\Delta P_{f i l m}-\zeta v_{\perp}=\frac{2 \gamma}{R_{c}}
$$

where $\zeta$ is a viscous drag force and $v_{\perp}$ is the film velocity component along the film normal. The left-hand side of equation 12 can then be calculated by measuring the foaming solution surface tension $\gamma$ and the curvature radius along the confining plates $R_{c}$. Surface tension of SDS solution at $17.33 \mathrm{mM}\left(5 \mathrm{~g} . \mathrm{L}^{-1}\right)$ is nearly $36.08 \mathrm{mN} \cdot \mathrm{m}^{-1}$. [15] $\mathrm{In}$ a previous work surface tension of AKYPO ${ }^{\circledR}$ solutions at different $\mathrm{pH}[16]$ was measured (see Table 1). From these experiments surface tension of AKYPO ${ }^{\circledR}$ solution at $\mathrm{pH} 12$ can be estimated at $38 \mathrm{mN} . \mathrm{m}^{-1}$. The pressure difference on both side of the foam film minus the viscous drag force can then be estimated for the two surfactants. In the case of SDS foam $\Delta P_{f i l m}-\zeta v_{\perp}$ varies between 0.05 and $0.42 \mathrm{mbar}$ for $14.2 \mathrm{~mm}$ and $1.7 \mathrm{~mm}$ curvature radius respectively, whereas for $A K Y P O \circledR$ it is between 0.11 and 2.02 mbar for $6.5 \mathrm{~mm}$ and $374 \mu \mathrm{m}$ curvature radius respectively (see Fig. 9, b). We could not measure film velocity here, but these results show that, considering a similar film velocity between the two surfactants due to same injection conditions, AKYPO ${ }^{\circledR}$ bamboo foam sustains a pressure gradient 5 times higher than SDS foam. As experimental conditions (pressure ratio, concentration, microfluidic device) and surface tension are quite similar for each system, the behaviour difference between the two may be attributed to the surfactant structure itself. AKYPO ${ }^{\circledR}$ surfactant is composed of an alkyl chain of 18 carbon and a polyethoxylated chain containing 9 oxygen atoms and a carboxylic function. These latest are highly hydrophilic which allowed AKYPO® to form foam stabilized by Gibbs monolayers or soluble monolayers (surfactant adsorption is reversible). The surfactant is highly soluble and when the foam or lamellae breakdown a monophasic liquid residue is obtained. In other hand, SDS is composed of a 12 carbon alkyl chain and a sulphate polar head. This structure makes SDS less hydrophilic than AKYPO® and allowed to form Langmuir monolayers or insoluble monolayers in hard water (irreversible adsorption leading to a rigid interface, usually for molecules with solubility lower than $10^{-6}$ $10^{-7} \mathrm{M}$ ). Furthermore, foam fractionation experiment on $17.33 \mathrm{mM}$ SDS solution (results not yet published) and precipitating SDS foams[43] have shown the formation of solid SDS residue on top of the foam and bubble surface. This solid monolayer behaviour could explain the deformation difference between the two surfactants: by adsorbing at the interface, SDS gives rise to a solid monolayer that could impact the surface viscoelasticity by increasing the elastic modulus which could lead to a lower flow (or pressure gradient) resistance and then to 
lamellae breakdown. Moreover, the area per head group for AKYPO® at $\mathrm{pH} 12$ is 96.9 $\AA^{2}[16]$ and is higher than the area per head group of SDS which is approximately equal to 60 $\AA^{2}$. $[44,45]$ This means that, the surface excess of AKYPO ${ }^{\circledR}$ is lesser than SDS which induces a lesser surface viscosity[6,38] and then flow resistance.

Finally, AKYPO ${ }^{\circledR}$ offers the possibility to tune the lamellae stability by varying $\mathrm{pH}$ and to generate foam lamellae in basic condition at higher pressure ratio than SDS.

\section{Conclusion}

This comparative study between SDS and AKYPO® RO $90 \mathrm{VG}$ at $17.33 \mathrm{mM}$ using microfluidic has demonstrated that, foam generation and morphology depend strongly on the injected fluid parameters such as gas and liquid pressure and are quite independent of physicochemical parameters such as $\mathrm{pH}$ and dodecanol concentration. The simple used micro-device has highlighted the five principal foam flow morphologies previously described for SDS surfactant but newly observed for AKYPO ${ }^{\circledR}$. The impact of the physicochemical parameters was highlighted in the lamella regime at high pressure ratio, underlining the fact that, $A K Y P O \AA$ foam becomes more stable in basic conditions due to deprotonation of the surfactant head group which increases the disjoining pressure by electrostatic repulsion in the lamella. In other hand, the addition of dodecanol in SDS solution, known to increase the interface viscosity, has only a slightly impact on the flowing lamellae except at high concentration where lamella's shape becomes double bump due to the accumulation of surfactant (and co-surfactant) in the front of the bubble.

The comparison between these two surfactants has pointed out some differences in the lamellae shape and stability domain. AKYPO ${ }^{\circledR}$ at $\mathrm{pH} 12$ allows to form lamellae even at very high pressure ratio whereas SDS lamellae break down. Furthermore the AKYPO® lamella curvature radius increases when pressure ratio increases whereas that one for SDS keeps almost constant. This difference is attributed to the surfactants solubilities and structure.

These particular and tuneable properties of AKYPO ${ }^{\circledR}$ make it a potential candidate for oil extraction in EOR context[34] as diverting agent or gas mobility control agent due to its capacity to form lamellae at high pressure ratio in large micro-channel (1.2 mm width).

This study reveals the crucial relevance of physicochemical parameters on flowing foam in porous media that are sometimes ignored on EOR experimental studies[10] or modified by the native rock oil reservoir. Perspectives of this work will be studies on other physicochemical parameters such as ionic strength, nature of salt or temperature that has been 
already studied on 3D-bulk foam,[16,46] as well as in the presence of oil in order to better understand the oil/foam interaction in porous media.

\section{References}

[1] I. Cantat, S. Cohen-Addad, F. Elias, F. Graner, R. Hölher, O. Pitois, F. Rouyer, A. Saint-Jalmes, Les Mousses: Structures et dynamique, Belin, Paris, 2010.

[2] C. Micheau, A. Schneider, L. Girard, P. Bauduin, Evaluation of ion separation coefficients by foam flotation using a carboxylate surfactant, A collection of papers presented at the 5 th European Conference on Foams, Emulsions, and Applications, EUFOAM 2004, University of Marne-la-Vallee, Champs sur Marne (France), 5-8 July, 2004470 (2015) 52-59.

[3] C. Dame, C. Fritz, O. Pitois, S. Faure, Relations between physicochemical properties and instability of decontamination foams, A collection of papers presented at the 5 th European Conference on Foams, Emulsions, and Applications, EUFOAM 2004, University of Marne-laVallee, Champs sur Marne (France), 5-8 July, 2004263 (2005) 210-218.

[4] E.D. Prete, A. Chinnayya, A. Hadjadj, L. Domergue, J.F. Haas, B. Imbert, Modeling of aqueous foam blast wave attenuation, EPJ Web of Conferences 10 (2010).

[5] T.S. Kristiansen, T. Holt, Properties of Flowing Foam in Porous Media Containing Oil (1992).

[6] A. Huerre, V. Miralles, M.C. Jullien, Bubbles and foams in microfluidics, Soft Matter 10 (2014) 6888-6902.

[7] B. Dollet, S.A. Jones, Y. Méheust, I. Cantat, Influence of the Elastic Deformation of a Foam on its Mobility in Channels of Linearly Varying Width, Physical Review E 90 (2014) 023006.

[8] L.L. Schramm, A.T. Turta, J.J. Novosad, Microvisual and Coreflood Studies of Foam Interactions With a Light Crude Oil, SPE-20197-PA (1993).

[9] P. Grassia, E. Mas-Hernández, N. Shokri, S.J. Cox, G. Mishuris, W.R. Rossen, Analysis of a model for foam improved oil recovery, Journal of Fluid Mechanics 751 (2014) 346-405.

[10] M. Simjoo, Y. Dong, A. Andrianov, M. Talanana, P.L.J. Zitha, Novel Insight Into Foam Mobility Control, SPE-163092-PA (2012).

[11] N. Quennouz, M. Ryba, J.F. Argillier, B. Herzhaft, Y. Peysson, N. Pannacci, Microfluidic Study of Foams Flow for Enhanced Oil Recovery (EOR), Oil Gas Sci. Technol. Rev. IFP Energies nouvelles 69 (2014) 457-466.

[12] A.R. Kovscek, H.J. Bertin, Foam Mobility in Heterogeneous Porous Media (I: Scaling Concepts), Transport in Porous Media 52 (2003) 17-35.

[13] R.A. Ettinger, C.J. Radke, Influence of Texture on Steady Foam Flow in Berea Sandstone, SPE19688-PA (1992).

[14] W.T. Osterloh, Jante,M. J. Jr., Effects of Gas and Liquid Velocity on Steady-State Foam Flow at High Temperature, SPE-24179-PA (1992).

[15] S.A. Jones, B. Dollet, Y. Méheust, S.J. Cox, I. Cantat, Structure-Dependant Mobility of a Dry Aqueous Foam Flowing Along Two Parallel Channels, Physics of Fluids 25 (2013) 063101-1. 
[16] C. Micheau, P. Bauduin, O. Diat, S. Faure, Specific Salt and pH Effects on Foam Film of a pH Sensitive Surfactant, Langmuir 29 (2013) 8472-8481.

[17] R. Sedev, D. Exerowa, DLVO and non-DLVO surface forces in foam films from amphiphilic block copolymers, Advances in Colloid and Interface Science 83 (1999) 111-136.

[18] A. Andrianov, R. Farajzadeh, M. Mahmoodi Nick, M. Talanana, P.L.J. Zitha, Immiscible Foam for Enhancing Oil Recovery: Bulk and Porous Media Experiments, Ind.Eng.Chem.Res. 51 (2012) 2214-2226.

[19] J. Marchalot, J. Lambert, I. Cantat, P. Tabeling, M.-C. Jullien, 2D Foam Coarsening in a Microfluidic System, EPL 83 (2008) 64006.

[20] M. Schwarze, M. Gross, M. Moritz, G. Buchner, L. Kapitzki, L. Chiappisi, M. Gradzielski, Micellar enhanced ultrafiltration (MEUF) of metal cations with oleylethoxycarboxylate, Journal of Membrane Science 478 (2015) 140-147.

[21] M. Schwarze, L. Chiappisi, S. Prévost, M. Gradzielski, Oleylethoxycarboxylate: An efficient surfactant for copper extraction and surfactant recycling via micellar enhanced ultrafiltration, Journal of Colloid and Interface Science 421 (2014) 184-190.

[22] D.C. Duffy, J.C. McDonald, O.J.A. Schueller, G.M. Whitesides, Rapid Prototyping of Microfluidic Systems in Poly(dimethylsiloxane), Anal.Chem. 70 (1998) 4974-4984.

[23] B.T. Ginn, O. Steinbock, Polymer Surface Modification Using Microwave-Oven-Generated Plasma, Langmuir 19 (2003) 8117-8118.

[24] T. Gervais, J. El-Ali, A. Günther, K.F. Jensen, Flow-induced deformation of shallow microfluidic channels, Lab on a chip 6 (2006) 500-507.

[25] J.P. Fang, P. Joos, The dynamic surface tension of SDS-dodecanol mixtures 2. Micellar SDSdodecanol mixtures, Colloids and Surfaces 65 (1992) 121-129.

[26] A.W. Goodman, G. Goodman, Generalizations of the Theorems of Pappus, The American Mathematical Monthly 76 (1969) 355-366.

[27] A. van der Net, L. Blondel, A. Saugey, W. Drenckhan, Simulating and interpretating images of foams with computational ray-tracing techniques, A collection of papers presented the 5 th European Conference on Foams, Emulsions, and Applications, EUFOAM 2004, University of Marne-la-Vallee, Champs sur Marne (France), 5-8 July, 2004309 (2007) 159-176.

[28] T. Cubaud, C.-M. Ho, Transport of Bubbles in Square Microchannels, Physics of Fluids 16 (2004) 4575-4585.

[29] K.T. Chambers, C.J. Radke, Micromodel Foam Flow Study, U.S. Department of Energy, Berkeley, 1990.

[30] J.-P. Raven, Generation, Flow and Manipulation of a Microfoam. Ph D Thesis, Université Joseph Fourier - Grenoble I, 2007.

[31] J.P. Raven, P. Marmottant, Periodic Microfluidic Bubbling Oscillator: Insight into the Stability of Two-Phase Microflows, Phys.Rev.Lett. 97 (2006) 154501.

[32] O. Claussen, S. Herminghaus, M. Brinkmann, Packings of monodisperse emulsions in flat microfluidic channels, Physical review. E, Statistical, nonlinear, and soft matter physics 85 (2012) 061403.

[33] J.P. Raven, P. Marmottant, F. Graner, Dry microfoams: formation and flow in a confined channel, The European Physical Journal B - Condensed Matter and Complex Systems 51 (2006) 137-143.

[34] C. Micheau, Tensioactif carboxylique polyéthoxylé pour la flottation ionique, Étude fondamentale de la solution à la mousse, PhD Thesis, Université Montpellier II, 2013. 
[35] V. Bergeron, D. Langevin, A. Asnacios, Thin-Film Forces in Foam Films Containing Anionic Polyelectrolyte and Charged Surfactants, Langmuir 12 (1996) 1550-1556.

[36] F.P. Bretherton, The motion of long bubbles in tubes, Journal of Fluid Mechanics 10 (1961) 166188.

[37] O. Pitois, C. Fritz, M. Vignes-Adler, Liquid drainage through aqueous foam: study of the flow on the bubble scale, Journal of Colloid and Interface Science 282 (2005) 458-465.

[38] M. Durand, D. Langevin, Physicochemical approach to the theory of foam drainage, The European Physical Journal E 7 (2002) 35-44.

[39] M. Clausse, L. Nicolas Morgantini, A. Zradba, D. Touraud, Water/ionic surfactant/alkanol/hydrocarbon system, Microemulsion Systems. New York, NY: Marcel Dekker (1987) 15-63.

[40] A. Haugen, M.A. Ferno, A. Graue, H.J. Bertin, Experimental Study of Foam Flow in Fractured OilWet Limestone for Enhanced Oil Recovery, SPE-129763-MS (2012).

[41] D.Y.C. Chan, E. Klaseboer, R. Manica, Theory of non-equilibrium force measurements involving deformable drops and bubbles, Advances in Colloid and Interface Science 165 (2011) 70-90.

[42] P. Grassia, G. Montes-Atenas, L. Lue, T.E. Green, A foam film propagating in a confined geometry: Analysis via the viscous froth model, European Physical Journal E 25 (2008) 39-49.

[43] L. Zhang, A. Mikhailovskaya, P. Yazhgur, F. Muller, F. Cousin, D. Langevin, N. Wang, A. Salonen, Precipitating Sodium Dodecyl Sulfate to Create Ultrastable and Stimulable Foams, Angew.Chem.Int.Ed. (2015) n/a.

[44] W.M. Gelbart, A. Ben-Shaul, D. Roux, Micelles, Membranes, Microemulsions and Monolayers, Springer-Verlag, New-York, 1994.

[45] D. Jurasin, I. Habus, N. Filipovic-Vincekovic, Role of the alkyl chain number and head groups location on surfactants self-assembly in aqueous solutions, A collection of papers presented at the 5th European Conference on Foams, Emulsions, and Applications, EUFOAM 2004, University of Marne-la-Vallee, Champs sur Marne (France), 5-8 July, 2004368 (2010) 119-128.

[46] A.L. Fameau, A. Saint-Jalmes, F. Cousin, Houinsou,Houssou,B., B. Novales, L. Navailles, F. Nallet, C. Gaillard, F. Boué, J.P. Douliez, Smart Foams: Switching Reversibly between Ultrastable and Unstable Foams, Angew.Chem.Int.Ed. 50 (2011) 8264-8269. 